\title{
Application of surface-modified metal hydrides for hydrogen separation from gas mixtures containing carbon dioxide and monoxide
}

\author{
M. Lototskyy, K.D. Modibane, M. Williams, Ye. Klochko, V. Linkov and B.G. Pollet
}

\begin{abstract}
Application of surface-modified $\mathrm{MH}$ material for $\mathrm{H}_{2}$ separation using temperature/pressure swing absorption-desorption was studied. The substrate alloy had the following composition LaNi3.55Coo.75Alo.4-Mno.3, and the surface modification was carried out through fluorination followed by aminosilane functionalization and electroless deposition of $\mathrm{Pd}$. The material was found to have good poisoning tolerance towards surface adsorbates, even for the large (rv1.5 kg) batches. Feasibility of its application for $\mathrm{H}_{2}$ separation from gas mixtures (up to $30 \% \mathrm{CO}_{2}$ and 100 ppm CO) was demonstrated by testing of a prototype $\mathrm{H}_{2}$ separation system (rv280 $\mathrm{g}$ of $\mathrm{MH}$ in two reactors), and $\mathrm{H}_{2}$ separation reactor ( $0.75 \mathrm{~kg}$ of $\mathrm{MH}$ ). The $\mathrm{H}_{2}$ separation was characterized by stable performances in the duration of 250 absorption/desorption cycles. However, the total process productivity was found to be limited by the sluggish $\mathrm{H}_{2}$ absorption (partial $\mathrm{H}_{2}$ pressure 62.5 bar, temperature below $100{ }^{\circ} \mathrm{C}$ ). In the presence of $\mathrm{CO}_{2}$ and $\mathrm{CO}$, additional deceleration of $\mathrm{H}_{2}$ absorption was observed at space velocities of the feed gas below $5000 \mathrm{~h}$
\end{abstract}

\section{Introduction}

Selectivity of reversible hydrogen interaction with hydride-forming materials allows for the development of simple and efficient pressure/temperature swing absorptiondesorption systems for hydrogen separation from complex gas mixtures and its fine purification $[1,2]$. However, so far, this approach was successfully implemented only for hydrogen-rich feed gases (vent streams in the ammonia synthesis loop, $\mathrm{H}_{2}>50 \%$ ) which contain relatively innocuous admixtures, mainly nitrogen and argon [3,4]. At the same time, the gases associated with processing of coal, petrol, natural gas and other carbonaceous/fossil fuels feedstock, in addition to hydrogen, may contain significant amounts of other components, mainly carbon dioxide and monoxide, which in most cases cause the deterioration of hydrogen sorption performances of metal hydrides (MHs) $[5,6]$. 
Earlier the authors reported on the improvement of activation performances and poisoning tolerance of $\mathrm{AB}_{5}$-type hydride-forming materials surface-modified by fluorination and/or electroless deposition of metals (including Pd), possessing high catalytic activity towards the dissociative $\mathrm{H}_{2}$ chemisorptive process [7]. The development of a prototype $\mathrm{H}_{2}$ separation and purification system based on the advanced $\mathrm{MH}$ materials [8] successfully demonstrated its feasibility for $\mathrm{H}_{2}$ separation from gas mixtures containing $\mathrm{CO}_{2}$ and $\mathrm{CO}$.

This investigation presents results of further feasibility studies focused on the integration of the materials in $\mathrm{H}_{2}$ separation and purification systems. Special attention and care was paid to the upscaling effect in the implementation of $\mathrm{MH}$ for $\mathrm{H}_{2}$ separation.

\section{Experimental}

Selection of the substrate $\mathrm{MH}$ materials and applied operation conditions (pressure, temperature, and feed gas composition) was based upon typical application requirements (processing of a carbonaceous feedstock including desulphurization, steam reforming and water-gas shift reaction). The experimental conditions assumed operation in the temperature range $5 \mathrm{O}-80{ }^{\circ} \mathrm{C}$ (selective $\mathrm{H}_{2}$ absorption at its partial pressure in the mixture up to 2.5 bar) to $200{ }^{\circ} \mathrm{C}\left(\mathrm{H}_{2}\right.$ desorption at rv1 bar).

The substrate material used in this study was an $\mathrm{AB}_{5}$-type battery alloy ( $A=\mathrm{La}$; $B=\mathrm{Ni}_{0.71}$ Coo.15 $\mathrm{Mn}_{0.06} \mathrm{Al}_{\mathrm{O}} .08$ ) purchased from Guangzhou Research Institute of Non-Ferrous Metals (China). According to XRD (Bruker AXS D8 Advance, Cu Ka, $\left.\lambda_{1}=1.5406 \AA, \lambda_{2}=1.5444 \AA, \lambda_{2} / \lambda_{1}=0.5,2 \theta=10-90^{\circ}\right)$, the material contained single $\mathrm{AB}_{5}$ phase with lattice parameters $\mathrm{a}=5.06750(7) \AA \mathrm{c}=4.0382(1) \AA$

The equilibrium hydrogen absorption/desorption performances (PCTs) of the substrate were studied using a PCT Pro-2000 gas sorption analyzer (Hy-Energy LLC) in the ranges $T=50-200{ }^{\circ} \mathrm{C}$ and $P=0-50$ bar. The collected data were further processed by the model of phase equilibria in metal-hydrogen systems [9] facilitating the calculation of the equilibrium hydrogen concentrations in the $\mathrm{MH}(C)$ at any given hydrogen pressure $(P)$ and temperature $(T)$. The material was found to have a maximum hydrogen storage capacity of $\sim 6.6 \mathrm{H} / \mathrm{AB}_{5}(175 \mathrm{~cm} 3 / \mathrm{g} \mathrm{STP})$ at $T=20^{\circ} \mathrm{C}$ and $P_{\mathrm{H} 2}=100$ bar. The reversible $\mathrm{H}$ capacity of the material (absorption at $2.5 \mathrm{bar} / 80{ }^{\circ} \mathrm{C}$; desorption at $1 \mathrm{bar} / 200{ }^{\circ} \mathrm{C}$ ) was determined as $127.5 \mathrm{~cm} 3 / \mathrm{g}$ STP, which is higher than the corresponding value of $89.5 \mathrm{~cm} 3 / \mathrm{g}$ STP for the previously studied Mischmetal-based $\mathrm{AB}_{5}$ [7].

Surface modification of the $\mathrm{AB}_{5}$ substrate (powder 200 mesh/ $74 \mathrm{~lm}$ ) was carried out by fluorination, followed by aminosilane functionalization and electroless deposition of $\mathrm{Pd}$, according to the procedure described in $[10,11]$. Distinct from the previous studies, 
where small quantities ("'5 g) of the sample were prepared, the present work attempted to upscale the surface modification procedure. The design of the surface modification reactors (100 $\mathrm{g}$ to $10 \mathrm{~kg}$ of the substrate powder per load) was based upon the following considerations: (i) chemical stability towards acidic/ alkaline media; (ii) sufficient agitation of the material; and (iii) effective mixing of reagents. Two reactors based on "impeller" (0.1-1.5 kg MH) and "tumble/drum" (1-10 kg MH; see inset in Fig. 1) mixing of the reagents were developed and tested in the course of this activity.

The activation performances of the surface-modified materials were evaluated by measurement of $\mathrm{H}_{2}$ absorption kinetics $\left(\mathrm{PH}_{2}=5\right.$ bar; $\left.T=20{ }^{\circ} \mathrm{C}\right)$ in a Sieverts-type volumetric installation, without activation by vacuum heating, after the materials were exposed to air (no less than two weeks) prior to the experiment.

In addition, rates of selective absorption of $\mathrm{H}_{2}$ (25\%) from feed gas, containing up to $30 \%$ $\mathrm{CO}_{2}$ and up to $0.33 \% \mathrm{CO}$ (balance $-\mathrm{N}_{2}$; gas mixtures of specified compositions supplied by Air Liquide South Africa), were measured. The experiments were carried out in a running flow mode with a space velocity up to $40,000 \mathrm{~h}^{\mathbf{- 1}}$. MH powder ( $m$ "' $4 \mathrm{~g}$ ) was loaded in a tubular reactor with internal diameter of $10 \mathrm{~mm}$. Activation of the $\mathrm{MH}$ sample and determination of amount of $\mathrm{H}_{2}$ absorbed from the feed gas $\left(\mathrm{C}_{H}\right)$ for the specified period of time ( $t$ MAX) was carried out using a Sieverts-type volumetric installation attached to the experimental setup. Hydrogen absorption rates, $r$, in the running-flow mode were estimated using simplified thermal calculations according to formula:

$$
r=C_{H} \frac{\Delta T}{\int_{0}^{r_{\text {Mux }}} \Delta T d t}
$$

where $\mathrm{D} T$ is the difference between actual $(T)$ and starting $\left(T_{\mathrm{O}}\right)$ sample temperature, $t$ is time.

Despite Eq. (1) is a rough simplification which results in a lagging of the calculated reaction rates behind real ones, for the applied experimental conditions the deviations were found to be quite small (see Supplementary information). Thus Eq. (1) can be used for the comparison of hydrogenation rates at different feed gas compositions.

Further experimental details can be found in [7].

The first prototype of the experimental $\mathrm{H}_{2}$ separation system included two runningflow reactors (140 $\mathrm{g}$ of the surface-modified $\mathrm{MH}$ material per reactor) equipped with electric heaters and air coolers whose operation was synchronized with switching gas flows by motorized valves. The reactors were operated in opposite 
phases, i.e. $\mathrm{H}_{2}$ absorption from the feed gas in a cooled reactor with the simultaneous desorption of pure $\mathrm{H}_{2}$ from the heated reactor.

The second prototype running-flow $\mathrm{MH}$ reactor for $\mathrm{H}_{2}$ separation was made as a stainless steel cylinder; the internal space of the reactor, $\varnothing_{45} \times 150 \mathrm{~mm}$. The reactor comprised a water-cooled heat exchanger and was filled with $750 \mathrm{~g}$ of the surface-modified $\mathrm{MH}$ material. Heating of the reactor was carried out by a bracket electric heater.

Both prototypes were tested using a specially designed test rig (supply pressure -10 bar; output pressure of pure $\mathrm{H}_{2}-1-1.5$ bar; feed gas flow rate $-1-10 \mathrm{~L} / \mathrm{min}$; maximum heating temperature $-200{ }^{\circ} \mathrm{C}$ ). The gas composition (mixture input, mixture output, $\mathrm{H}_{2}$ output) was monitored using a QMC2OO mass spectrometer (Stanford Research Systems Inc.) equipped with a capillary for sampling atmospheric pressure gas. The details on design and operation of the $\mathrm{H}$ separation system (first prototype) and the test rig are presented in [8].

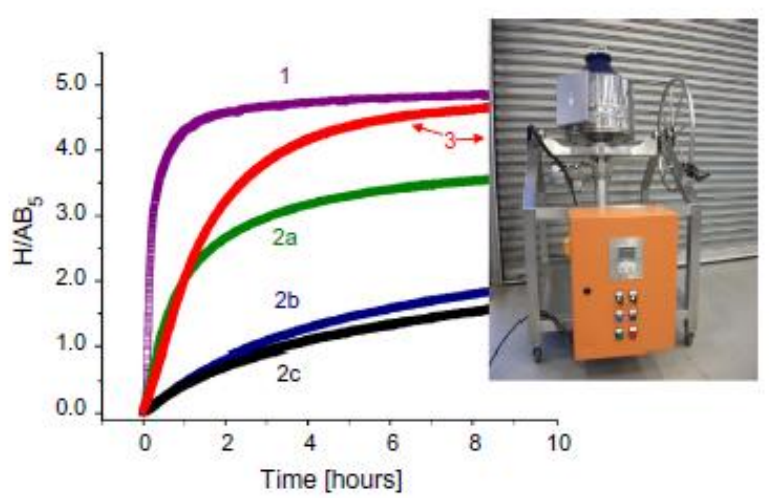

Fig. 1. $\mathrm{H}$ absorption in non-activated $\mathrm{La}(\mathrm{Ni}, \mathrm{Co}, \mathrm{Al}, \mathrm{Mn})_{5}\left(5\right.$ bar $\left.\mathrm{H}_{2} / 20^{\circ} \mathrm{C}\right)$ surface modified by fluorination - aminosilane functionalization - Pd electroless deposition using various batch sizes of the substrate: (1) Laboratory sample: $m=5 \mathrm{~g}$ : (2) "Impeller" mixing: $\mathrm{m}=100 \mathrm{~g}$ (a), $300 \mathrm{~g}$ (b), and $1 \mathrm{~kg}$ (c); and (3) "tumble/drum" mixing: $m=1.5 \mathrm{~kg}$. The inset shows reactor realizing "tumble/drum" mixing (option 3; up to $10 \mathrm{~kg} \mathrm{MH}$ load).

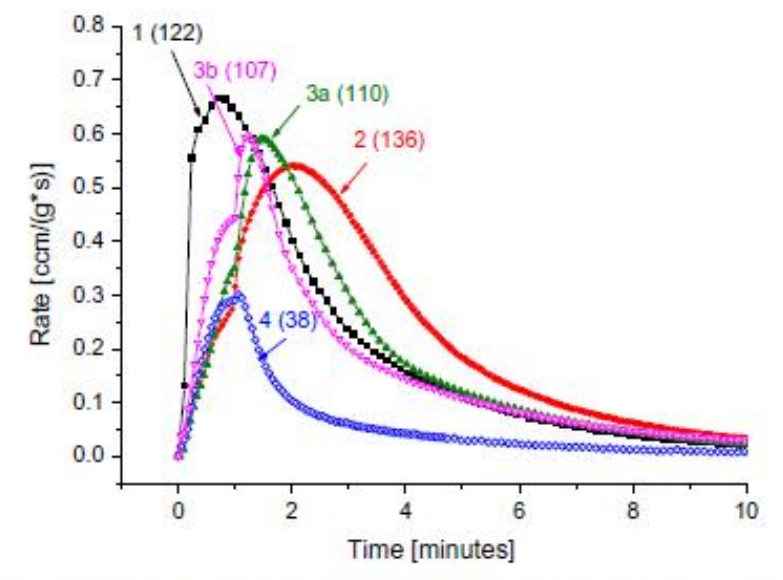

Fig. 2. Dynamics of $\mathrm{H}_{2}$ absorption by the surface-modified $\mathrm{La}(\mathrm{Ni}, \mathrm{Co}, \mathrm{Al}, \mathrm{Mn})_{5}$ alloy in running-flow mode at $T_{0}=20^{\circ} \mathrm{C}$. The partial $\mathrm{H}_{2}$ pressure and flow rate are 2 bar and $0.25 \mathrm{~L} / \mathrm{min}$, respectively. The values in brackets correspond to maximum hydrogen absorption capacity $\left[\mathrm{cm}^{3} / \mathrm{g}\right.$ STP]: (1) Pure $\mathrm{H}_{2}$; (2) $25 \% \mathrm{H}_{2}+10 \% \mathrm{CO}_{2}+\mathrm{N}_{2}$ (balance); (3) $25 \% \mathrm{H}_{2}+10 \% \mathrm{CO}_{2}+100$ ppm CO $+\mathrm{N}_{2}$ (balance); (a) cycle \# 1 , and (b) cycle \#16; and (4) $25 \% \mathrm{H}_{2}+28 \% \mathrm{CO}_{2}+0.33 \% \mathrm{CO}+\mathrm{N}_{2}$ (balance).

\section{Results and discussion}

Express screening of the activation performances of the prepared batches of the surface-modified $\mathrm{AB}_{5}$-type material (kinetics of hydrogen absorption at mild conditions, see Fig. 1) showed that when increasing the batch size, the hydrogen absorption kinetics deteriorated significantly as compared to the $5 \mathrm{~g}$ laboratory sample prepared using magnetic stirring (curve 1). The deterioration was more pronounced for the samples prepared using the "impeller" mixing system (curves $2 \mathrm{a}-\mathrm{c}$ ), and was associated with insufficient agitation of the alloy powder (density about $8 \mathrm{~g} / \mathrm{cm} 3$ ) and the solution used in surface modification ( $\mathrm{rv1} \mathrm{g} / \mathrm{cm} 3$ ). Improved results were obtained using the "tumble/drum" mixing system which provided more intensive agitation, which 
resulted in a uniform distribution of the coating on the surface of the substrate (confirmed by SEM) and subsequent rapid kinetics of hydrogen charging (curve 3), which compared well to the laboratory sample.

Fig. 2 presents the experimental data on selective $\mathrm{H}_{2}$ absorption by the surface-modified material (from $1.5 \mathrm{~kg}$ batch) at room temperature and various feed gas compositions. No significant deterioration of $\mathrm{H}_{2}$ absorption rate from the feed gas containing up to $10 \%$ $\mathrm{CO}_{2}$ and up to $100 \mathrm{ppm} \mathrm{CO}$ was observed. Deterioration occurred only where mixtures containing $0.33 \% \mathrm{CO}$ and $28 \% \mathrm{CO}_{2}$ (curve 4) were used. The effect of slow reaction rates, in this case, resulted in the decrease of the hydrogen absorption capacity achieved in $10-15 \mathrm{~min}$ to $25-30 \mathrm{~cm} 3 / \mathrm{g}$ within 3 cycles, and remained approximately the same in the subsequent cycles. Note that for the unmodified materials hydrogen absorption capacity dropped to almost zero in rv5 cycles when operating on feed gas containing rv40 ppm CO.

Fig. 3 summarizes test results of the first prototype $\mathrm{H}_{2}$ separation system. The gas separation process is characterized by 'stable' performances when operating on feed gases containing $25 \%$ of $\mathrm{H}_{2}$, up to $30 \%$ of $\mathrm{CO}_{2}$, and up to $100 \mathrm{ppm}$ of $\mathrm{CO}$. Introduction of $\mathrm{CO}_{2}$ and $\mathrm{CO}$ into the feed gas resulted in a slight (rv20\%) decrease of the average output productivity as compared to that observed upon introduction of the $\mathrm{H}_{2}+\mathrm{N}_{2}$ mixture. However, no further decreases in the productivity were observed within the first 500 operation cycles (250 absorption/desorption cycles for each reactor), in the absence of regeneration (re-activation by the vacuum heating). The main impurities in the output hydrogen (MS analysis) when operating in the feed gas mixture $25 \% \mathrm{H}_{2}+30 \% \mathrm{CO}_{2}+$ $100 \mathrm{ppm} \mathrm{CO}+\mathrm{N}_{2}$ (balance) were $\mathrm{N}_{2}+\mathrm{CO}$ (estimated concentration about $1 \%$ ), $\mathrm{CO}$ (rvo.5\%), water vapour (rvo.5\%) and light hydrocarbons ( 0.3\%). 

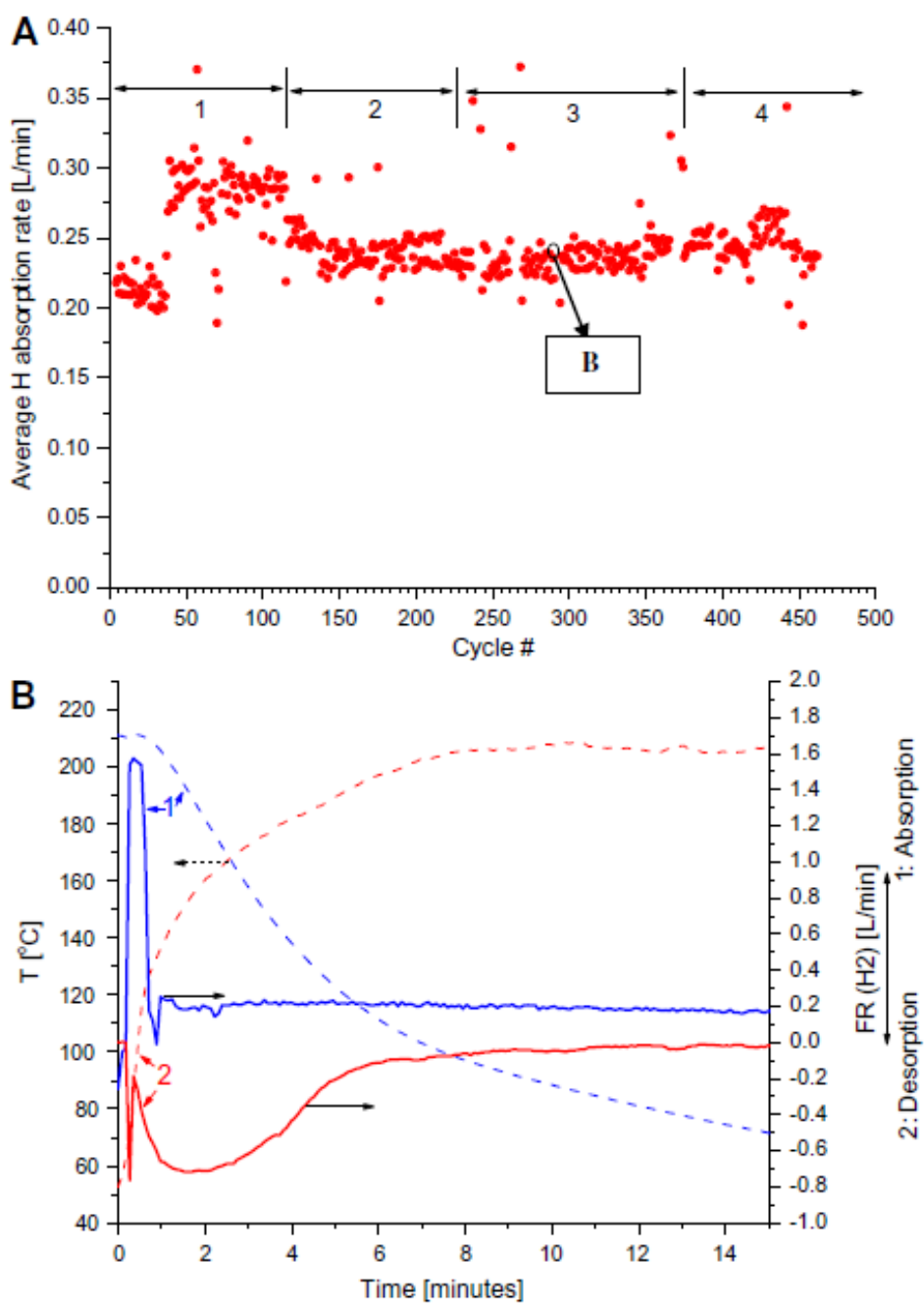

Fig. 3. (A) Average $\mathrm{H}_{2}$ absorption rates during the operation of the first prototype $\left(\mathrm{H}_{2}\right.$ separation system). Feed gas pressure 10 bar, output of pure $\mathrm{H}_{2}$ at 1 bar. Most of the cycles were carried out at the flow rate of feed gas $=1.5 \mathrm{~L} / \mathrm{min}$; deviations of the data from the general trend are mainly caused by the variations of this parameter ( $1 . .5 \mathrm{~L} /$ min). The ranges 1-4 correspond to the following compositions of the feed gas: (1) $25 \% \mathrm{H}_{2}+\mathrm{N}_{2} ;(2) 25 \% \mathrm{H}_{2}+10 \% \mathrm{CO}_{2}+100 \mathrm{ppm} \mathrm{CO}+\mathrm{N}_{2} ;(3) 25 \% \mathrm{H}_{2}+20 \% \mathrm{CO}_{2}+100 \mathrm{ppm}$ $\mathrm{CO}+\mathrm{N}_{2}$; and (4) $25 \% \mathrm{H}_{2}+30 \% \mathrm{CO}_{2}+100 \mathrm{ppm} \mathrm{CO}+\mathrm{N}_{2}$. (B) Typical operation cyclogram of the system (cycle \# 300). 


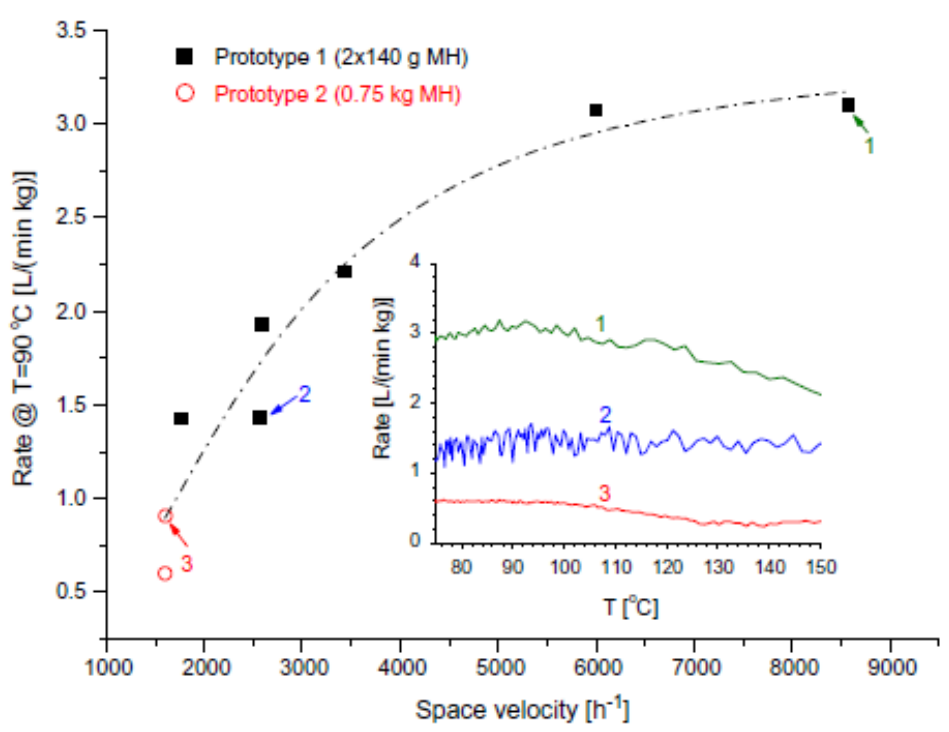

Fig. 4. Dependencies of $\mathrm{H}_{2}$ absorption rates on the space velocity of the feed gas $\left(25 \% \mathrm{H}_{2}+\mathrm{N}_{2}\right)$. The inset shows typical dependencies of the $\mathrm{H}_{2}$ absorption rates on the reactor temperature.

At the same time, the average productivity per cycle was only about $0.2 \mathrm{~L} \mathrm{H}_{2} / \mathrm{min}$, and was limited by slow hydrogen absorption in the material (see Fig. 3B). The main origin for this observation seems to be in the limitation of mass transfer in the gas phase at high (75\%) total concentration of the impurities in the feed gas and relatively low $\mathrm{H}_{2}$ partial pressure (2.5 bar), resulting in low driving force of $\mathrm{H}_{2}$ absorption.

As it can be observed from Fig. 4, summarizing results on $\mathrm{H}_{2}$ absorption rates at $\mathrm{T}=90{ }^{\circ} \mathrm{C}$ for the $\mathrm{MH} \mathrm{H}_{2}$ separation system (prototype 1) and the $\mathrm{MH} \mathrm{H}_{2}$ separation reactor (prototype 2), the rate of selective $\mathrm{H}_{2}$ absorption significantly depends upon the space velocity $(v)$ of the feed gas. When the space velocity decreases below $3000-5000 \mathrm{~h}^{-1}$, the decrease of $\mathrm{H}_{2}$ absorption rate becomes very pronounced. This finding can be explained by the decrease of $\mathrm{H}_{2}$ concentration in the proximity to the surface of $\mathrm{MH}$ material and the necessity to supply "fresh" volumes of the feed gas with higher $\mathrm{H}_{2}$ concentration to maintain higher absorption rates. Accordingly, the concentration of active impurities $\left(\mathrm{CO}_{2}\right.$ and $\left.\mathrm{CO}\right)$ at low space velocities becomes higher resulting in further deterioration of $\mathrm{H}$ absorption performances of the $\mathrm{MH}$ material. At $\mathrm{v}<2000$ $\mathrm{h}^{-1}$ the observed $\mathrm{H}_{2}$ absorption rate for $25 \% \mathrm{H}_{2}+30 \% \mathrm{CO}_{2}+100 \mathrm{ppm} \mathrm{CO}+\mathrm{N}_{2}$ mixture was about $60 \%$ of the corresponding value for $25 \% \mathrm{H}_{2}+\mathrm{N}_{2}$.

\section{Conclusions}

The feasibility of the application of $\mathrm{AB}_{5}$-type hydride-forming alloy materials surfacemodified by fluorination and electroless deposition of $\mathrm{Pd}$, for $\mathrm{H}_{2}$ separation from gas mixtures $\left(25 \% \mathrm{H}_{2}\right.$, up to $30 \% \mathrm{CO}_{2}$ and $\left.100 \mathrm{ppm} \mathrm{CO}\right)$, was demonstrated by the testing of prototype $\mathrm{H}_{2}$ separation system (rv280 g of $\mathrm{MH}$ in two reactors), and $\mathrm{H}_{2}$ separation 
reactor ( $0.75 \mathrm{~kg}$ of $\mathrm{MH})$. The $\mathrm{H}_{2}$ separation was characterized by stable performances within 250 absorption/ desorption cycles.

At the same time, the total process productivity was found to be limited by the slow selective $\mathrm{H}_{2}$ absorption under the process conditions. The $\mathrm{H}_{2}$ absorption was shown to be hindered by mass transfer in the gas phase at space velocities of feed gas below $5000 \mathrm{~h}^{-1}$. Special engineering solutions providing sufficient space velocities (e.g., by operation in flowing-circulation mode) are thus necessary for efficient application of $\mathrm{MH}$ to separate hydrogen from mixtures which contain high (x10\%) concentrations of accompanying gases.

\section{Acknowledgements}

This development was funded by ESKOM Holdings Ltd., South Africa. The materials research was also supported by National Research Foundation of South Africa (NRF) via the Program of research cooperation between Norway and South Africa (20072010, Project \#180344). The development of infrastructure for the testing of the prototype $\mathrm{H}_{2}$ separation system and reactor was supported by Department of Science and Technology of South Africa via HySA Program, project KP8-So1. ML also thanks NRF for the support via Incentive Funding Grant.

\section{Appendix A. Supplementary material}

Supplementary data associated with this article can be found, in the online version, at http://dx.doi.org/10.1016/j.jallcom.2013.02.096. 


\section{References}

[1] P. Dantzer, Metal-hydride technology: a critical review, in: H. Wipf (Ed.), Hydrogen in Metals, vol. III, Springer-Verlag, Berlin-Heidelberg, 1997.

[2] G. Sandrock, R.C. Bowman, J. Alloys Compds. 356-357 (2003) 794-799.

[3] J.J. Sheridan III, F.G. Eisenberg, E.J. Greskovich, J. Less-Common Met. 89 (1983) 447-455.

[4] M. Au, C. Chen, Z. Ye, T. Fang, J. Wu, O. Wang, Int. J. Hydrogen Energy 21 (1996) 33-37.

[5] G.D. Sandrock, P.D. Goodell, J. Less-Common Met. 104 (1984) 159-173.

[6] B.P. Tarasov, S.P. Shilkin, Russ. J. Appl. Chem. 68 (1995) 21-26.

[7] M.V. Lototsky, M. Williams, V.A. Yartys, Ye.V. Klochko, V.M. Linkov, J. Alloys Compds. 509 (2011) S555-S561.

[8] M. Lototskyy, M. Williams, Ye. Klochko, K.D. Modibane, V. Linkov, Hydrogen separation from $\mathrm{CO}_{2}-$ and CO-containing gases using surfacemodified metal hydrides, in: World Congress on Engineering and Technology (CET2011), Shanghai/China, October 28-30, 2011 (paper \# 0521-1914361).

[9] M.V. Lototsky, V.A. Yartys, V.S. Marinin, N.M. Lototsky, J. Alloys Compds. 356- 357 (2003) 27-31.

[10] M. Williams, M.V. Lototskyy, A.N. Nechaev, V.M. Linkov, Hydride forming material, Patent ZA 2008/09123.

[11] M. Williams, M.V. Lototsky, V.M. Linkov, A.N. Nechaev, J.K. Solberg, V.A. Yartys, Int. J. Energy Res. 33 (2009) 1171-1179. 